Article type : Letter to Editor

Title:

\title{
Marked pseudoepitheliomatous hyperplasia secondary to a red- pigmented tattoo: a case report
}

Key words: red tattoo, pseudoepitheliomatous hyperplasia, allergy disperse red, tattoo adverse reaction, red pigment tattoo

Authors: A.Tammaro, S.Raffa, N.Petrigliano, Z.Verdiana, E.Gelormini, E.Moliterni, F.Magri, F.R.Parisella, S.Persechino

NESMOS Department - Dermatology ,Sant'Andrea Hospital -Rome (Italy)

"Sapienza" University of Rome

Corresponding author: A. Tammaro

\author{
NESMOS Department - Dermatology \\ Sant'Andrea Hospital - Rome (Italy) \\ Via di Grottarossa, 1035-1039 \\ "Sapienza" University of Rome \\ tammaroantonella@gmail.com \\ $+390633775907$
}

We declare that no funding sources have supported our work.

Tattooing is gaining increasing popularity in developed countries in recent years.

Adverse cutaneous reactions of many different types against coumponds in tattoo inks are being reported more and more often in medical literature,especially against red-pigmented tattoo.

This article has been accepted for publication and undergone full peer review but has not been through the copyediting, typesetting, pagination and proofreading process, which may lead to differences between this version and the Version of Record. Please cite this article as doi: $10.1111 / \mathrm{jdv} .14806$

This article is protected by copyright. All rights reserved. 
Delayed immune-mediated reactions can manifest in several ways and different histological patterns have been described:

eczematous (in allergic contact or photoallergic dermatitis), lichenoid, granulomatous, pseudolymphomatous, sarcoidal, vasculitis and finally pseudoepitheliomatous hyperplasia. 1

The culprit, in most of the cases, is cinnabar red, the pigment in red ink, containing mercury sulphate. 2,3

We report the case of a marked pseudoepitheliomatous hyperplasia reaction which is an unusual and severe manifestation of allergic contact dermatitis to red pigments,

adding to the list of our previous reports. 4,5

A 36-years-old woman presented to our clinic with complaints of a painful, itchy, red, raised overgrowth over her 1-year-old cherries tattoo on the left leg that had been recently retouched with injections of new pigment.

On clinical inspection, an erythematous, oedematous, infiltrated,ulcerated plaque with leakage of red pigment was found to be precisely localized within the boundaries of the red-pigmented area with clearly demarked borders, leaving the other areas of the tattoo unaffected. Fig.1

Fungal and common bacterial infections were ruled out after negative cultural examinations.

A Patch test series SIDAPA (Euromedical) was performed that containing:

potassium dichromate, rosin, epoxy resin, formaldeidica resin,Euxil 400, neomycin sulphate, fragrance mix, nickel sulphate,mercaptobenzotiaziolo, paraphenylendiamine, cobalt chloride, balsam of peru, thiuram mix, benzocaine, lanolin alcohols, parabens, Vaseline, scattered yellow, scattered blue and hydroquinone.

It resulted positive (+++) for nickel sulphate at $72 \mathrm{~h}$.

In addition, we also perform a Patch Test special series for tattoos (FIRMA) to investigate on tattoo haptens: copper sulphate, dimethylaminobenzene, aminoazotoluene, disperse blue, disperse yellow, scattered orange, disperse red, gentian violet, cadmium chloride, nickel sulphate, iron chloride, potassium chrome, chrome trichloride, aminoazobenzene, cobalt chloride, aluminium chloride, titanium dioxide, zinc, mercury chloride, Kathon, fenolo, trihydrochloride ethylenediamine, phenylenediamine base, formaldehyde, phthalic anhydride, rosin, dibutyl phthalate, hexamethylenetetramine and benzophenonesulphate.

It showed positivity for disperse red (+) at $48 \mathrm{~h}$ and $(++)$ at $72 \mathrm{~h}$.

Histological study of a punch-biopsy specimen is characterized by acanthosis, papillomatosis, hyperkeratosis, and parakeratosis of the epidermis and by a strong lymphohistiocytic infiltrate in perivascular and periadnexal areas of the mid and superficial dermis. Fig. $2 \mathrm{~A}$

Scant pigmented histiocytes are also observed in the dermis. Fig.2 B

At the ultrastructural examination the inflammatory cells showed ink particles Fig. $2 \mathrm{C}$ surrounded by a membrane and included in lysosome-related structures. Fig.2 D

This article is protected by copyright. All rights reserved. 
These features are compatible with a dermatitic process whose underlying mechanism is a localized cell-mediated reaction (type IV hypersensivity) to tattoo red component.

The patient was treated with intralesional corticosteroids.

Pseudoepitheliomatous hyperplasia is a pattern of reactive skin reaction that clinically presents as an hyperkeratotic plaque lesion which is often infiltrated.

On histology, it is characterized by epidermal and follicular infundibulum acanthosis in the absence of atypia and with rare mitotic activity.

The differential diagnosis is with $\mathrm{BCC}, \mathrm{SCC}$, viral warts and verrucous carcinoma.

Interestingly, several cases of keratoacanthomatous lesions have also been described in the setting of a recent red-pigmented tattoo. 6,7

We observed many severe reactions in patients with retouched and freshly re-inked tattoos: injections of new, different pigments by a different tattoo artist frequently cause cross-reactions and re-puncturing causes epidermal lesions with breakage of the basal membrane and leakage of the pigments.

To conclude, there is a remarkable necessity of extensive researches about involved haptens, a compelling need to develop a more strict legislation to regulate the composition of inks and to be aware of the several types of reactions to tattoos, as these skin affections are expected to be increasingly encountered in dermatologic practice due to the widespread trend of tattooing as a body art and cosmetic permanent make-up.

1. Høgsberg T, Thomsen BM, Serup J. Histopathology and immune histochemistry of red tattoo reactions. Skin Res Technol 2015;21(4):449-458.

2. A.Tammaro,G.Cortesi,F.Pigliacelli et al. Heavy metals and tattoos: an allergy and legislative problem Eur Ann Allergy Clin Immunol 2016 Jul;48(4):153-5.

3. A.Tammaro,V.Giulianelli,S.Persechino,C.Toniolo,M.Serafini Chemical research on red pigments after adverse reactions to tattoo. Eur Ann Allergy Clin Immunol 1 March 2016, 48(2):46-48

4. A.Tammaro, A.Narcisi, G.Cortesi et al. A case of pseudoepitheliomatous hyperplasia to tattoos. JEADV July 2015, Vol. 29 Issue 7, p1439, 2 p.

5. A.Tammaro,C.Abruzzese,A.Narcisi et al. Localized pseudoepitheliomatous hyperplasia: unusual cutaneous reaction pattern to tattoo. Int Wound J 2016 Apr; Vol. 13 (2), pp. 294-5.

This article is protected by copyright. All rights reserved. 
6. N. Kluger, L.Durand, C.Minier-Thoumin et al. Pseudoepitheliomatous epidermal hyperplasia in tattoos:report of three cases. Am J Clin Dermatol. Sept-Oct, 2008, Vol. 9 Issue 5, p337, 4 p.

7. N.Kluger. Issues with keratoacanthoma, pseudoepitheliomatous hyperplasia and squamous cell carcinoma within tattoos: a clinical point of view. J Cutan Pathol. 2009;37(7):812-813.

Figure1. Hyperplastic,ulcerated lesion on red-pigmented areas of a tattoo placed on the patient left leg.

Figure2. A. Epidermis with acanthosis, papillomatosis and hyper-parakeratosis and dermis characterized by a strong lymphohistiocytic infiltrate in perivascular and periadnexal areas (Hematoxylin and eosin staining 10X) B. Pigment-laden cells in perivascular location and scattered in the dermis (Hematoxylin and eosin staining 40X). C and D. Perivascular inflammatory cells containing tattoo ink particles bound by a membrane. [TEM, uranyl acetate/lead citrate; Morgagni 268D Electron Microscopy - FEI Company, Hillsboro]

This article is protected by copyright. All rights reserved. 


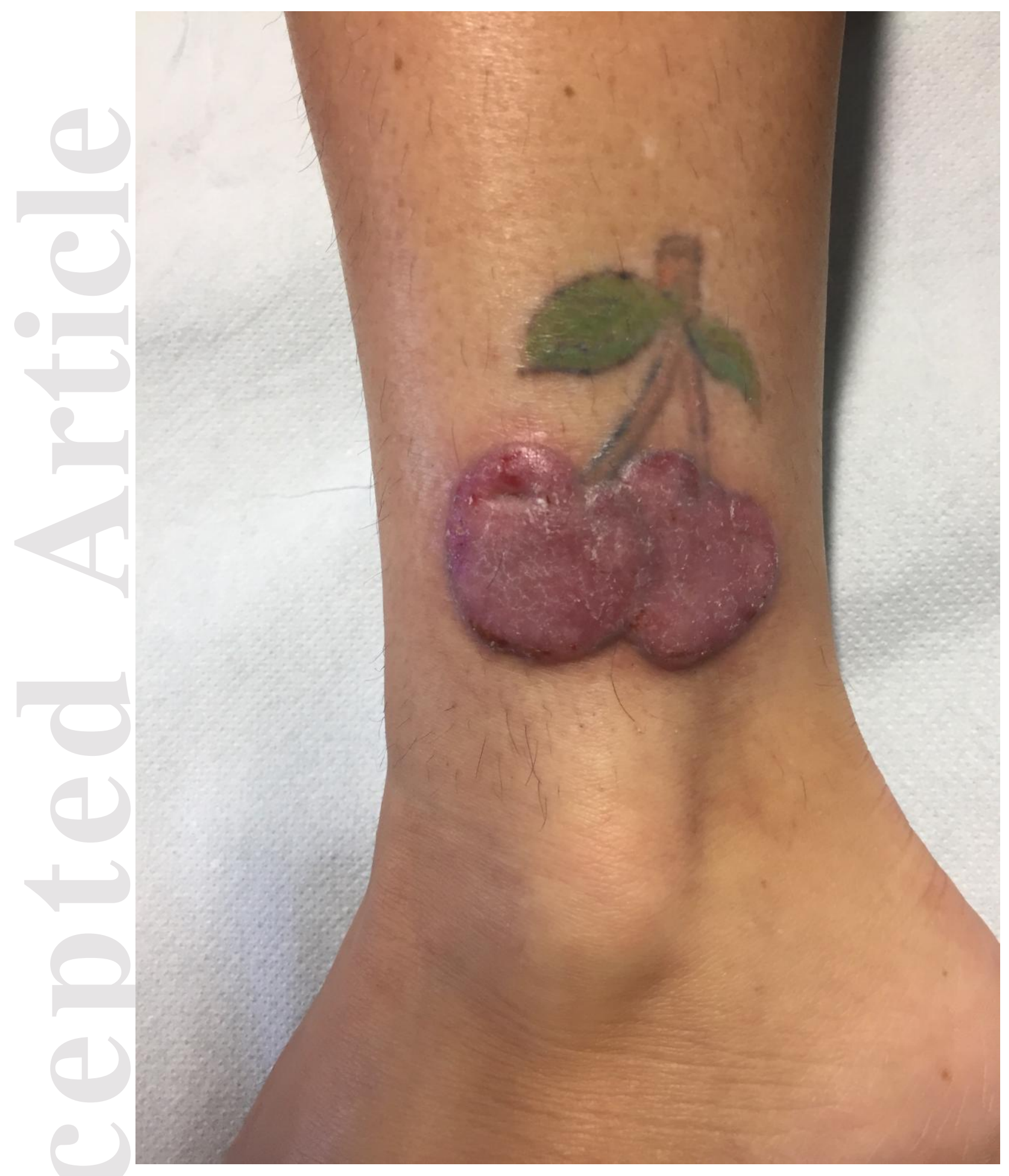

This article is protected by copyright. All rights reserved. 

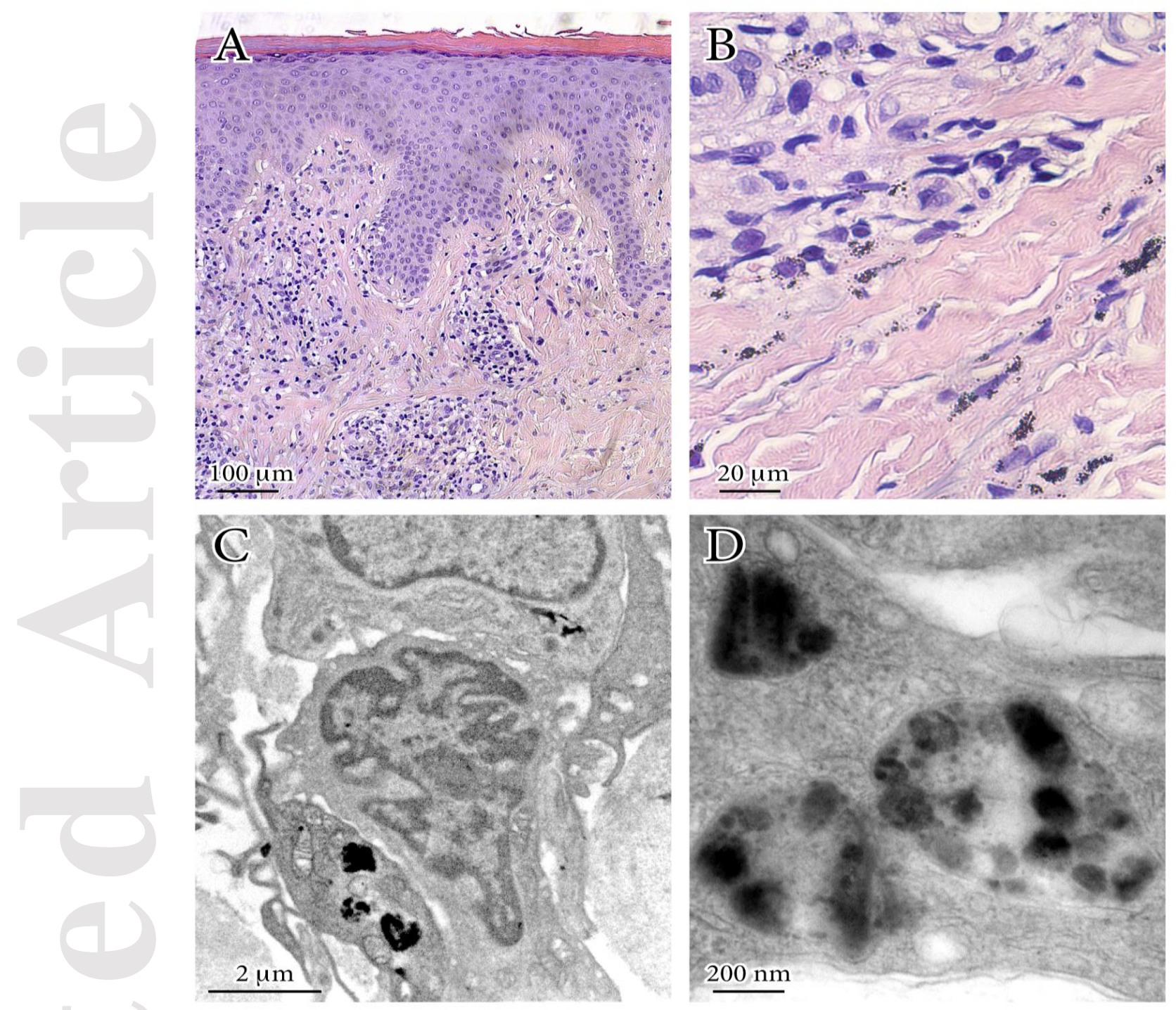

This article is protected by copyright. All rights reserved. 